08

\title{
Получение нанокристаллов соединений цинка электролитическим способом, используя различные электролиты
}

\author{
(ㄱ Н.Б. Данилевская, ${ }_{1}^{1}$ А.В. Лисица, ${ }^{1}$ Н.В. Мороз, ${ }^{2}$ Б.Д. Нечипорук, ${ }^{1}$ Н.Е. Новоселецкий, ${ }^{1}$ Б.П. Рудык ${ }^{2 q}$ \\ ${ }^{1}$ Ровенский государственный гуманитарный университет, \\ 33000 Ровно, Украина \\ ${ }^{2}$ Национальный университет водного хозяйства и природопользования, \\ 33028 Ровно, Украина \\ ฯ e-mail: rexismundi@gmail.com
}

(Поступило в Редакцию 11 июля 2017 г.)

\begin{abstract}
Представлены результаты исследования влияния состава электролита на процесс синтеза нанокристаллических порошков соединений цинка, полученных электролитическим методом. Показано, что при использовании электролита комнатной температуры, приготовленного растворением $\mathrm{Na}_{2} \mathrm{~S}_{2} \mathrm{O}_{3} \cdot 5 \mathrm{H}_{2} \mathrm{O}$, получается смесь сульфида цинка и гидроцинкита. При приготовлении электролита с использованием $\mathrm{Na}_{2} \mathrm{SO}_{3}$ или $\mathrm{Na}_{2} \mathrm{~S} \cdot 9 \mathrm{H}_{2} \mathrm{O}$ получается смесь оксида цинка и гидроцинкита или смесь сульфида цинка и гидроцинкита. Определены размеры соответствующих нанокристаллов. Установлено разложение гидроцинкита на оксид цинка, воду и углекислый газ в интервале температур $200-250^{\circ} \mathrm{C}$.
\end{abstract}

DOI: $10.21883 /$ JTF.2018.03.45601.2426

\section{Введение}

Оксид цинка - прямозонный полупроводниковый материал с шириной запрещенной зоны $3.37 \mathrm{eV}$ и высокой энергией связи экситона $~ 60 \mathrm{meV}$, что делает его перспективным материалом для создания различных оптоэлектронных устройств. Кроме того, $\mathrm{ZnO}$ имеет низкую стоимость, биологическую совместимость и высокую экологичность, вследствие чего находит практическое применение в полупроводниковой промышленности, медицине, химической технологии, косметике и фармакологии. Разнообразие путей получения, морфологии и размерности исследованных соединений открывает новые перспективы их применения в экологии, биотехнологии и биомедицине. Оксид цинка используют при изготовлении элементов солнечных батарей, светоизлучающих диодов видимого и ультрафиолетового излучения, прозрачных тонкопленочных транзисторов, пьезоэлектрических приборов, биосенсоров и различных датчиков. В последнее время интерес к $\mathrm{ZnO}$ значительно возрос в связи с возможностью его синтеза в наноструктурном виде [1-4]. Электролюминофоры на основе сульфида цинка с добавками таких активаторов, как Al, $\mathrm{Cl}$ и В, имеют коммерчески желаемые яркостные и цветовые характеристики. Этот класс электролюминофоров может создавать синее, зеленое или желто-оранжевое свечение [5].

Для получения нанокристаллов соединений цинка используют различные методы, в том числе: золь-гель осаждение, металлорганическое осаждение с газовой фазы, молекулярно-лучевая эпитаксия, магнетронный, термический методы лазерной абляции в жидкости, гидротермальный, химический, электролитический [6-9]. Описанные методы имеют свои преимущества и недостатки. Электрохимический, электролитический методы не нуждаются в сложной аппаратуре, высоких температурах и давлениях, дефицитных химических реактивах. Для их реализации можно применять различные источники тока: постоянного, переменного или переменного, наложенного на постоянный ток. Используя данные методы синтеза, один или два электрода изготовляют с металла, соединения которого необходимо получить, а остальные химические элементы могут входить в состав электролита. В случае оксидов и гидроксидов металла электролит, раствор соли в воде, обеспечивает его проводимость [10,11].

Цель работы - исследовать зависимость физических свойств полученных нанокристаллов соединений цинка электролитическим способом от состава и температуры электролита для выбора оптимальных режимов синтеза.

\section{Методика эксперимента}

Нанокристаллические порошки соединений цинка получены в стеклянном электролизере с цилиндрическими цинковыми электродами. В качестве электролита использовались растворы тиосульфата натрия (кристаллогидрат $\left.\mathrm{Na}_{2} \mathrm{~S}_{2} \mathrm{O}_{3} \cdot 5 \mathrm{H}_{2} \mathrm{O}\right)$, сульфита натрия $\left(\mathrm{Na}_{2} \mathrm{SO}_{3}\right)$ и натрия сернистого 9-водного $\left(\mathrm{Na}_{2} \mathrm{~S} \cdot 9 \mathrm{H}_{2} \mathrm{O}\right)$ в дистиллированной воде. Питание электролизера осуществлялось от регулированного стабилизированного источника постоянного тока. Плотность тока в экспериментах составляла $1.3 \cdot 10^{-2} \mathrm{~A} / \mathrm{cm}^{2}$. Температура электролита изменялась в пределах от комнатной до $100^{\circ} \mathrm{C}$. Длительность синтеза составляла $3 \mathrm{~h}$. Для равномерного растворения цинковых электродов использовался реверс направления тока каждые $30 \mathrm{~min}$. После окончания синтеза полученные образцы фильтровались с помощью бумажного фильтра, промывались пятикратным объемом 
дистиллированной воды и высушивались при комнатной температуре.

Рентгеновские исследования выполнены при комнатной температуре на дифрактометре ДРОН-4 с использованием $\mathrm{Cu} K_{\alpha}$-излучения. Сканирование производилось при фокусировке по Брэггу-Брентано $(\theta-2 \theta)$. Анодное напряжение, ток, шаг сканирования дифрактограммы и время экспозиции составляли $41 \mathrm{kV}, 21 \mathrm{~mA}, 0.05^{\circ}$ и $5 \mathrm{~s}$ соответственно.

Кривые дифференциально-термического анализа (ДТА) сплавов записаны на приборе Н307-1 XY с использованием хромель-алюмелевых термопар. Термопары были предварительно откалиброваны по точкам плавления In $(429 \mathrm{~K}), \mathrm{Sn}(505 \mathrm{~K}), \mathrm{Cd}(594 \mathrm{~K})$, $\mathrm{Te}(723 \mathrm{~K}), \mathrm{Sb}(904 \mathrm{~K}), \mathrm{NaCl}(1074 \mathrm{~K}), \mathrm{Ge}(1209 \mathrm{~K})$, $\mathrm{Ag}(1236 \mathrm{~K}), \mathrm{Cu}(1357 \mathrm{~K})$ [12]. Скорость нагрева (охлаждения) образцов составляла $5-6^{\circ} \mathrm{C} / \mathrm{min}$. Погрешности значений температур структурных изменений сплавов не превышали $\pm 3^{\circ} \mathrm{C}$. ДТА выполнен как на воздухе, так и в вакуумированных до остаточного давления $\sim 1$ Ра ампулах из кварцевого стекла.

\section{Результаты и их обсуждение}

На рис. 1 показаны экспериментальные дифрактограммы образцов, полученных электролитическим способом при комнатной температуре. Электролит был приготовлен растворением в дистиллированной воде следующих солей: $a-$ тиосульфата натрия (кристаллогидрат $\left.\mathrm{Na}_{2} \mathrm{~S}_{2} \mathrm{O}_{3} \cdot 5 \mathrm{H}_{2} \mathrm{O}\right) ; b-$ сульфита натрия $\left(\mathrm{Na}_{2} \mathrm{SO}_{3}\right) ; c-$ натрия сернистого 9-водного $\left(\mathrm{Na}_{2} \mathrm{~S} \cdot 9 \mathrm{H}_{2} \mathrm{O}\right)$. Концентрации электролитов рассчитывали таким образом, чтобы весовое содержание серы у всех было одинаковым.

Экспериментальные дифрактограммы были описаны функцией Гаусса и получены характеристики рентгеновских рефлексов: угловое положение $2 \theta$, полуширина $\beta$ (ширина на половине высоты рефлекса), интегральная

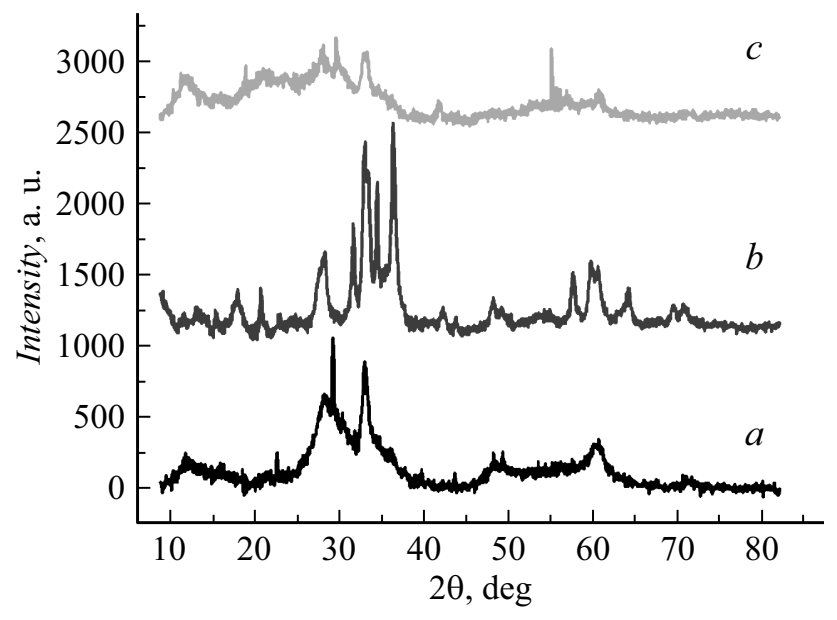

Рис. 1. Рентгеновские дифрактограммы образцов, полученных в электролитах: $a-\mathrm{Na}_{2} \mathrm{~S}_{2} \mathrm{O}_{3} \cdot 5 \mathrm{H}_{2} \mathrm{O} ; b-\mathrm{Na}_{2} \mathrm{SO}_{3} ; c-$ $\mathrm{Na}_{2} \mathrm{~S} \cdot 9 \mathrm{H}_{2} \mathrm{O}$. интенсивность I. В случае электролита, содержащего тиосульфат натрия (рис. $1, a)$, регистрируются рефлексы с угловым положением $2 \theta: 28.4^{\circ}, 47.9^{\circ}$ и $55.2^{\circ}$, которые индексируются как (111), (220) и (311) кубической сингонии сульфида цинка соответственно. Значительная полуширина рефлексов свидетельствует о малых размерах частиц. Кроме того, на дифрактограмме присутствуют интенсивные рефлексы с угловым положением $12.8^{\circ}, 29.4^{\circ}, 33.0^{\circ}, 59.4^{\circ}$. Анализ литературных источников $[13,14]$ показал, что данные рефлексы характерны для гидроцинкита $-\mathrm{Zn}_{5}\left(\mathrm{CO}_{3}\right)_{2}(\mathrm{OH})_{6}$.

При использовании электролита, содержащего сульфит натрия (рис. $1, b$ ), регистрируются интенсивные рефлексы с угловым положением $2 \theta: 31.8^{\circ}, 34.5^{\circ}, 36.4^{\circ}$, $47.6^{\circ}, 56.7^{\circ}$ и $62.8^{\circ}$, которые индексируются как (100), (002), (101), (102), (110), (103) гексагональной сингонии оксида цинка соответственно. Кроме того, на дифрактограмме присутствуют рефлексы гидроцинкита, интенсивность которых значительно выше по сравнению с рис. $1, a$.

Из анализа рис. 1, $c$ можно сделать вывод, что в случае использования электролита с $\mathrm{Na}_{2} \mathrm{~S} \cdot 9 \mathrm{H}_{2} \mathrm{O}$ присутствуют рефлексы, характерные для сульфида цинка $\left(2 \theta: 28.0^{\circ}\right.$, $47.6^{\circ}$ и $\left.55.1^{\circ}\right)$ и гидроцинкита $\left(2 \theta: 12.5^{\circ}, 29.6^{\circ}, 33.1^{\circ}\right.$ и $59.7^{\circ}$ ). По сравнению с дифрактограммой рис. $1, a$ интенсивность рефлексов сульфида цинка меньше, а гидроцинкита выше.

Для оценки размера нанокристалов была использованая формула Дебая-Шеррера [15]:

$$
D=0.89 \lambda /(\beta \cos \theta)
$$

где $\lambda$ - длина волны рентгеновского излучения, $\beta$ полуширина рефлекса (ширина на половине высоты) и $\theta$ - угловое положение рефлекса.

Физическое значение полуширины определяли по формуле

$$
\beta=\left(\beta_{1}^{2}-\beta_{2}^{2}\right)^{1 / 2}
$$

где $\beta_{1}$ - экспериментальное значение полуширины, определенное при описании рефлекса функцией Гаусса, $\beta_{2}$ - инструментальное значение полуширины, которое определялось при анализе дифрактограмм эталонных порошков кремния и $\mathrm{Al}_{2} \mathrm{O}_{3}$, полученных при одинаковых условиях. В случае использования нескольких рефлексов определялись средние значения. Для определения размера нанокристаллов $\mathrm{ZnS}$ (электролит $\mathrm{Na}_{2} \mathrm{~S}_{2} \mathrm{O}_{3} \cdot 5 \mathrm{H}_{2} \mathrm{O}$ ) использовались рефлексы с индексами Миллера (111), (220) и (311); $\mathrm{ZnO}$ (электролит $\left.\mathrm{Na}_{2} \mathrm{SO}_{3}\right)-(100),(002)$, (101), (102), (110), (103). Для определения размера нанокристаллов гидроцинкита были использованы рефлексы с индексом Миллера (200) или (020), а для $\mathrm{ZnS}$ (электролит $\mathrm{Na}_{2} \mathrm{~S} \cdot 9 \mathrm{H}_{2} \mathrm{O}$ ) - рефлекс (111). Полученные размеры нанокристаллов представлены в таблице.

Подобные результаты были получены авторами роботы [16] при получении нанокристаллов оксида цинка 
Размеры нанокристаллов

\begin{tabular}{c|l|c|c|c}
\hline \multirow{2}{*}{ № п/п } & \multicolumn{1}{|c|}{ Электролит } & $\begin{array}{c}(\mathrm{ZnS}) \\
D, \mathrm{~nm}\end{array}$ & $\begin{array}{c}\mathrm{ZnO} \\
D \mathrm{~nm}\end{array}$ & $\begin{array}{c}\left(\mathrm{Zn}_{5}\left(\mathrm{CO}_{3}\right)_{2}(\mathrm{OH})_{6}\right) \\
D, \mathrm{~nm}\end{array}$ \\
\hline 1. & $\mathrm{Na}_{2} \mathrm{~S}_{2} \mathrm{O}_{3} \cdot 5 \mathrm{H}_{2} \mathrm{O}$ & 1.8 & - & 2.3 \\
2. & $\mathrm{Na}_{2} \mathrm{SO}_{3}$ & - & 25.1 & 5.6 \\
3. & $\mathrm{Na}_{2} \mathrm{~S} \cdot 9 \mathrm{H}_{2} \mathrm{O}$ & 1.6 & - & 2.3
\end{tabular}

электролитическим способом с использованием раствоpa $\mathrm{NaCl}$ в качестве электролита. На рентгеновских дифрактограммах присутствовали рефлексы оксида цинка и гидроцинкита, причем интенсивность рефлексов гидроцинкита увеличивалась при уменьшении температуры электролита и увеличении концентрации $\mathrm{NaCl}$, что свидетельствует об увеличении содержания гидроцинкита. Размеры гидроцинкита, определенные с использованием формулы Дебая-Шеррера, при изменении условий синтеза изменялись в пределах $4-13 \mathrm{~nm}$, а оксида цинка $13.2-31.5 \mathrm{~nm}$.

Использование формулы Дебая-Шеррера предполагает, что полуширина зависит от размера частиц, которая увеличивается с уменьшением размера. Но известно, что на значение полуширины также влияют механические напряжения, которые возникают за счет дефектов кристаллической структуры, поскольку значительное количество атомов в случае нанокристаллов находится на их поверхности. Поэтому для разделения вкладов размерного эффекта и механических напряжений был использован метод Вильямсона-Холла [15]. Здесь полуширина рентгеновского рефлекса описывается выражением

$$
\beta=0.89 \lambda /(D \cos \theta)+4 \varepsilon \operatorname{tg} \theta,
$$

где $\lambda-$ длина волны рентгеновского излучения, $\varepsilon-$ относительное удлинение. Либо

$$
\beta \cos \theta=0.89 \lambda / D+4 \varepsilon \sin \theta .
$$

Для упругих деформаций за законом Гука механическое напряжение равно

$$
\sigma=E \varepsilon,
$$

где $E$ - модуль Юнга. Определив относительное удлинение и подставив в (4), получим

$$
\beta \cos \theta=0.89 \lambda / D+(4 \sigma \sin \theta) / E .
$$

В системе координат $4 \sin \theta / E, \beta \cos \theta$ зависимость (6) является линейной функцией, анализируя которую, можно определить размер нанокристаллов $D$ и действующее механическое напряжение $\sigma$. Для монокристаллов модуль Юнга будет зависеть от направления внутри монокристалла и типа кристаллической системы [17], эта зависимость описывается уравнениями (7) и (8) для кубической и гексагональной систем соответственно

$$
\begin{gathered}
E^{-1}=s_{11}-\left(2 s_{11}-2 s_{12}-s_{44}\right)\left(h^{2} k^{2}+k^{2} l^{2}-l^{2} h^{2}\right) / \\
/\left(h^{2} k^{2}+k^{2} l^{2}-l^{2} h^{2}\right)^{2} \\
E^{-1}=\left[\left(h^{2}+k^{2}-h k\right) a^{4} s_{11}+l^{4} c^{4} s_{33}\right. \\
\left.+\left(h^{2}+k^{2}-h k\right) l^{2} a^{2} c^{2}\left(s_{44}+2 s_{13}\right)\right] / \\
/\left[\left(h^{2}+k^{2}-h k\right) a^{2}+l^{2} c^{2}\right]^{2}
\end{gathered}
$$

где $s_{11}, s_{12}, s_{13}, s_{33}, s_{44}$ - коэффициенты упругой податливости, $a$ и $c$ - параметры кристаллической решетки, $h k l$ - индексы Миллера. Использовав известные коэффициенты упругой податливости и параметры кристаллической решетки для сульфида и оксида цинка [18], а также индексы рефлексов, которые зарегистрированы на дифрактограммах, мы предварительно рассчитали значения модуля Юнга в зависимости от направления внутри монокристалла.

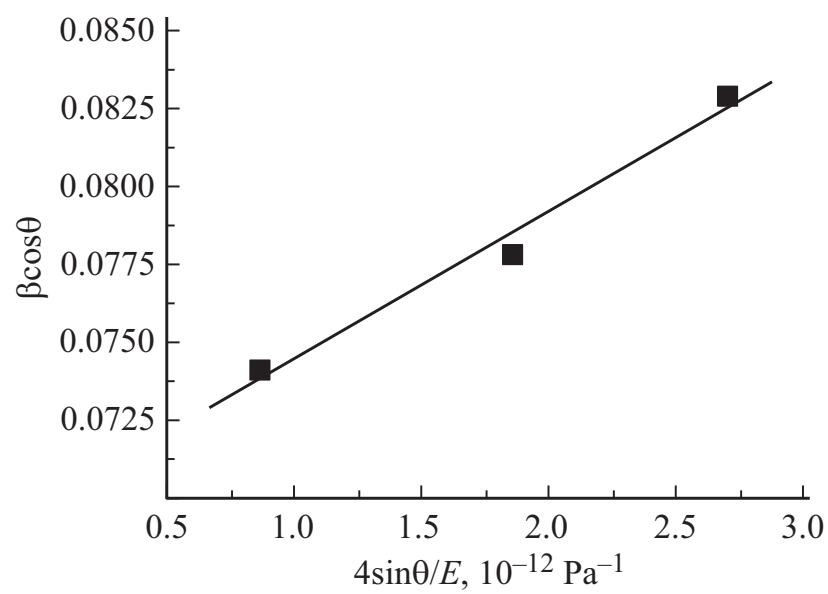

Рис. 2. Использование метода Вильямсона-Холла для определения размеров и напряжений нанокристаллов $\mathrm{ZnS}$ (электролит $\left.\mathrm{Na}_{2} \mathrm{~S}_{2} \mathrm{O}_{3} \cdot 5 \mathrm{H}_{2} \mathrm{O}\right)$.

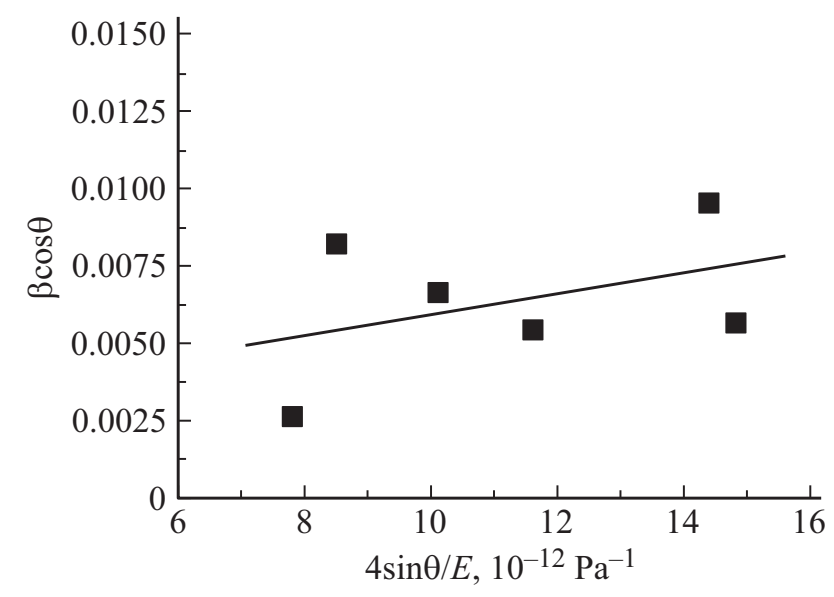

Рис. 3. Использование метода Вильямсона-Холла для определения размеров и напряжений нанокристаллов $\mathrm{ZnO}$ (электролит $\left.\mathrm{Na}_{2} \mathrm{SO}_{3}\right)$. 


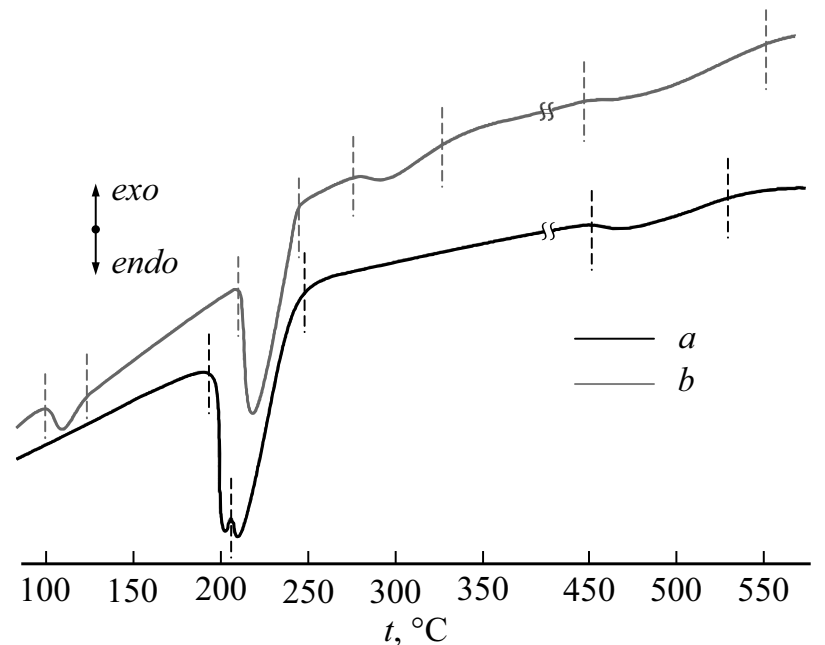

Рис. 4. Дифференциальный термический анализ образцов, полученных в электролитах: $a-$ сульфита натрия $\left(\mathrm{Na}_{2} \mathrm{SO}_{3}\right)$; $b$ - натрия сернистого 9-водного $\left(\mathrm{Na}_{2} \mathrm{~S} \cdot 9 \mathrm{H}_{2} \mathrm{O}\right)$.

На рис. 2 показаны результаты применения метода Вильямсона-Холла для наночастиц сульфида цинка, полученного используя электролит на основе тиосульфата натрия. Для экстраполяции экспериментальных точек линейной функцией использовался метод наименьших квадратов. В результате было получено, что размер нанокристаллов составляет $D=2.0 \mathrm{~nm}$, а механическое напряжение растяжения $\sigma=4.7 \cdot 10^{9} \mathrm{~Pa}$. Видно, что размер наночастиц, определенный методом ВильямсонаХолла, превышает результаты, полученные с использованием формулы Дебая-Шеррера.

На рис. 3 показаны результаты применения метода Вильямсона-Холла для наночастиц оксида цинка, полученного с использованием электролита на основе сульфита натрия. Расчеты показали, что размер нанокристаллов оксида цинка равен $D=52.1 \mathrm{~nm}$, а механическое напряжение растяжения $\sigma=3.4 \cdot 10^{8} \mathrm{~Pa}$. Таким образом, установлено, что размер наночастиц, определенный методом Вильямсона-Холла, существенно превышает результаты использования формулы Дебая-Шеррера.

На рис. 4 показаны результаты дифференциального термического анализа образцов, полученных с использованием электролитов: $\mathrm{Na}_{2} \mathrm{SO}_{3}$ (кривая $a$ ) и $\mathrm{Na}_{2} \mathrm{~S} \cdot 9 \mathrm{H}_{2} \mathrm{O}$ (кривая $b$ ). Отсутствие тепловых эффектов на кривой $a$ нагрева ДТА в окрестности $100^{\circ} \mathrm{C}$ свидетельствует о том, что материал не склонен к адсорбированию влаги. При дальнейшем нагреве ампулы зафиксировано два эндотермических тепловых эффекта при $197^{\circ} \mathrm{C}$ и $205^{\circ} \mathrm{C}$. Визуальным анализом охлажденной ампулы установлено наличие воды на стенках кварцевого контейнера. Вода удалялась путем разгерметизации ампулы и последующим ее нагревом до $125^{\circ} \mathrm{C}$. При повторном нагреве сплава от комнатной температуры в вакуумированной ампуле зафиксирован размытый в шкале температур $455-532^{\circ} \mathrm{C}$ эндотермический тепловой эффект.
Согласно рентгеноструктурным исследованиям данный образец состоит из смеси нанокристаллов оксида цинка и гидроцинкита. Поэтому образование воды можно объяснить разложением гидроцинкита по реакции, в результате которой образуются оксид цинка, углекислый газ и вода:

$$
\mathrm{Zn}_{5}\left(\mathrm{CO}_{3}\right)_{2}(\mathrm{OH})_{6} \rightarrow 5 \mathrm{ZnO}+2 \mathrm{CO}_{2}+3 \mathrm{H}_{2} \mathrm{O}
$$

Авторы работ $[19,20]$ наблюдали эндотермические эффекты при исследовании гидроцинкита методом термогравиметрического анализа и ДТА при температурах 245 и $250^{\circ} \mathrm{C}$. В нашем случае температура немного ниже, возможно по причине исследования смеси оксида цинка и гидроцинкита.

Из анализа кривой $b$ рис. 4 следует, что материал склонен к незначительному адсорбированию влаги, на что указывает малый по величине тепловой эффект на термограмме нагрева образца в окрестности $100^{\circ} \mathrm{C}$. После разгерметизации ампулы и удаления влаги при $125^{\circ} \mathrm{C}$ материал повторно вакуумировался и подвергался нагреву. На кривой ДТА обнаружен тепловой эффект при $210^{\circ} \mathrm{C}$. Как и в случае для кривой $a$ (рис. 4), пик обусловлен разложением гидроцинкита по реакции (9), в результате которой образуются оксид цинка, углекислый газ и вода. Выделившаяся вода была удалена разгерметизацией ампулы и последующим ее нагревом до температуры $125^{\circ} \mathrm{C}$. При последующем нагреве вакуумированного материала на кривой ДТА зафиксировано изменение структуры сплава при $275^{\circ} \mathrm{C}$. Визуальный осмотр охлажденной ампулы также указывал на наличие в ампуле незначительного количества воды. Это, возможно, обусловлено тем, что после первого нагрева не вся масса гидроцинкита разложилась. Авторы роботы [21] проводили изотермический отжиг гидроцинкита и установили, что разложение происходит при изменении температуры в пределах $150-275^{\circ} \mathrm{C}$, но скорость разложения существенно увеличивается с возрастанием температуры. Кроме того, в нашем случае исследуется смесь гидроцинкита и сульфида цинка.

\section{Заключение}

Показано, что результат получения нанокристаллов сульфида и оксида цинка электролитическим способом существенно зависит от состава электролита. При использовании электролита, полученного растворением соли $\mathrm{Na}_{2} \mathrm{~S}_{2} \mathrm{O}_{3} \cdot 5 \mathrm{H}_{2} \mathrm{O}$ в воде, получена смесь сульфида цинка и гидроцинкита, $\mathrm{Na}_{2} \mathrm{SO}_{3}$ - смесь оксида цинка и гидроцинкита, $\mathrm{Na}_{2} \mathrm{~S} \cdot 9 \mathrm{H}_{2} \mathrm{O}$ - смесь сульфида цинка и гидроцинкита. По результатам дифференциального термического анализа установлено, что в области температур $200-250^{\circ} \mathrm{C}$ наблюдается разложение гидроцинкита на оксид цинка и воду. 


\section{Список литературы}

[1] Абдуллин Х.А., Габдуллин М.Т., Гриценко Л.В., Исмаилов Д.В., Калкозова Ж.К., Кумеков С.Е., Мукаш Ж.О., Сазонов А.Ю., Теруков Е.И. // ФТП. 2016. Т. 50. Вып. 8. C. $1030-1035$.

[2] Лядов Н.М., Гумаров А.И., Кашапов Р.Н., Носков А.И., Валеев В.Ф., Нужсин В.И., Базаров В.В., Хайбуллин Р.И., Файзрахманов И.А. // ФТП. 2016. Т. 50. Вып. 1. С. 44-50.

[3] Raguvaran R., Manuja A., Manuja B.K. // Immunome Res. 2015. Vol. 11. N 2. P. $1000095(1)-1000095(8)$.

[4] Haq I.U., Azad A.M. // Sensors. 2012. Vol. 12. N 6. P. 8259-8277.

[5] Крылов П.Н., Закирова Р.М., Князев И.А., Костенков Н.В., Романов Э.А., Федотова И.В. // ФТП. 2015. Т. 49. C. $1371-1375$.

[6] Kumar V.S.S., Rao K.V. // J. Nano Electron. Phys. 2013. Vol. 5. N 2. P. 02026-1-02026-6.

[7] Бураков В.С., Невар Е.А., Неделько М.И., Тарасенко Н.В. // Письма в ЖТФ. 2008. Т. 34. Вып. 16. С. 1-8.

[8] Светличный В.А., Лапин И.Н. // Изв. вузов. Физика. 2013. Т. 56. Вып. 5. С. 86-91.

[9] Гаевський В.Р., Нечипорук Б.Д., Новоселецький М.Ю., Рудик Б.П. // УФЖ. 2013. Т. 58. Вып. 4. С. 388-391.

[10] Beedri N., Inamdar Y., Sayyed S.A., Shaikh A., Jadkar S., Pathan H. // Chem. Chem. Technol. 2014. Vol. 8. N 3. P. 283-286.

[11] Лаворик Ю.Ф., Нечипорук Б.Д., Новоселецкий Н.Е., Парасюк О.В., Рудык Б.П., Филоненко В.В. Патент Украины № 92078, 2010.

[12] Preston-Thomas H. The International Temperature Scale of 1990 (ITS-90). Metrologia 27. Springer, 1990. C. 3-10.

[13] Salahuddin N.A., El-Kemary M., Ibrahim E.M. // Nanosci. Nanotech. 2015. Vol. 5. N 4. P. 82-88.

[14] Wen-Zhong W., Yu-Jie L., Hong-Long S., Gu-Ling Z. // Chin. Phys. Lett. 2014. Vol. 31. N 9. P. 097802.

[15] Mote V.D., Purushotham Y., Dole B.N. // J. Theor. Appl. Phys. 2012. Vol. 6. N 1. P. 1-8.

[16] Danilevska N.B., Moroz M.V., Nechyporuk B.D., Novoseletskyy N.Yu., Rudyk B.P. // J. Phys. Stud. 2016. Vol. 20. N 3. P. 3601-1-3601-5.

[17] Сиротин Ю.И., Шаскольская М.П. Основы кристаллофизики. М.: Наука, 1975. 680 с.

[18] Adachi S. Handbook on physical properties of semiconductors. Springer, 2004. Vol. 3. 1471 p.

[19] Cheng J., Poduska K.M. // Nanomaterials. 2013. Vol. 3. N 3. P. 317-324.

[20] Haq I.U., Azad A.-M. // Sensors. 2012. Vol. 12. P. 8259-8277.

[21] Kanari N., Mishra D., Gaballah I., Dupré B. // Thermochim. Acta. 2004. Vol. 410. N 1-2. P. 93-100. 